\title{
Heart Rate Variability and Hypercapnia in Duchenne Muscular Dystrophy
}

\author{
Hitoshi Mochizuki ${ }^{1,2}$, Satomi Okahashi ${ }^{1}$, Yoshikazu Ugawa ${ }^{2}$, Takuhisa Tamura ${ }^{1}$, \\ Mikiya Suzuki ${ }^{1}$, Satoko Miyatake ${ }^{1}$, Toshiki Shigeyama ${ }^{3}$, \\ Katsuhisa Ogata ${ }^{1}$ and Mitsuru Kawai ${ }^{1}$
}

\begin{abstract}
Objective To investigate the relationship between heart rate variability and hypercapnia.

Patients and Methods We measured the coefficient of variation of R-R interval (CVrr) and arterial blood gas pressures in 73 patients with Duchenne muscular dystrophy.

Results CVrr was negatively correlated with arterial partial pressure of carbon dioxide $\left(\mathrm{PaCO}_{2}\right)$. In patients whose CVrr was larger than 5\%, $84 \%$ of them had no hypercapnia while the other $16 \%$ had hypercapnia $\left(\mathrm{PaCO}_{2}>45 \mathrm{mmHg}\right)$. In contrast, $27 \%$ of those with $\mathrm{CVrr}$ smaller than $3 \%$ had no hypercapnia, $73 \%$ had hypercapnia and $47 \%$ had severe hypercapnia $\left(\mathrm{PaCO}_{2}>50 \mathrm{mmHg}\right)$.

Conclusion We first showed that $\mathrm{CVrr}$ was negatively correlated with $\mathrm{PaCO}_{2}$, and propose that abnormally low CVrr indicates respiratory insufficiency in patients with Duchenne muscular dystrophy.
\end{abstract}

Key words: Duchenne muscular dystrophy, hypercapnia, heart rate variability, coefficient of variation of the $\mathrm{R}-\mathrm{R}$ interval

(Inter Med 47: 1893-1897, 2008)

(DOI: 10.2169/internalmedicine.47.1118)

\section{Introduction}

In patients with Duchenne muscular dystrophy (DMD) a characteristic pattern of respiratory functional changes is observed during childhood and adolescence. Vital capacity (VC) increases until around the age of 10 years similar to the usual development pattern, remains stable for a considerable period, then continuously falls in association with the progression of respiratory muscle weakness. The annual decrease in VC may be as much as $250 \mathrm{~mL}$ in the late teenage years (1). Respiratory failure is a major cause of death in DMD patients. Without ventilatory support, the mean lifetime is about 19 years, and $73 \%$ of DMD patients die of respiratory insufficiency (2). However, mechanical ventilation has extended patient survival time by more than five years (3-5).

Since the tracheostomy positive pressure ventilation
(TPPV) is more difficult to deliver at home than the noninvasive positive pressure ventilation (NPPV), most patients use NPPV first, and when hypercapnia cannot be managed by NPPV, they use TPPV (3). We should monitor the degree of respiratory failure in order to start TPPV at an appropriate time. For monitoring respiratory failure, usually arterial partial pressure of carbon dioxide $\left(\mathrm{PaCO}_{2}\right)$ is followed. However, often there is a difficulty in repeated blood gas analyses due to very slender arteries and articular contracture. Another reliable method for respiratory function analysis is VC measurement. In DMD patients, however, this measurement sometimes becomes inaccurate due to orbicularis oris muscle weakness, macroglossia and mental retardation.

On the other hand, the heart rate variability is a wellcharacterized, noninvasive means of assessing cardiac autonomic nervous system activity (6). The coefficient of the R$\mathrm{R}$ interval variation $(\mathrm{CVrr})$ reflects parasympathetic activity

${ }^{1}$ Department of Neurology, Higashi-Saitama National Hospital, Hasuda, ${ }^{2}$ Department of Neurology, School of Medicine, Fukushima Medical University, Fukushima and ${ }^{3}$ Department of Cardiology, Higashi-Saitama National Hospital, Hasuda

Received for publication March 14, 2008; Accepted for publication August 4, 2008

Correspondence to Dr. Hitoshi Mochizuki, mochizuki-h@umin.ac.jp 
Table 1. Clinical Features of Patients with Duchenne Muscular Dystrophy

\begin{tabular}{|c|c|c|c|c|c|c|c|c|c|c|c|}
\hline & \multicolumn{2}{|c|}{$\begin{array}{l}\text { All patients } \\
\qquad(\mathrm{n}=73)\end{array}$} & \multicolumn{2}{|c|}{$\begin{array}{l}\text { 1. No-V } \\
(n=21)\end{array}$} & \multicolumn{2}{|c|}{$\begin{array}{l}\text { 2. NPPV } \\
(n=27)\end{array}$} & \multicolumn{2}{|c|}{$\begin{array}{l}\text { 3. TPPV } \\
(\mathrm{n}=25)\end{array}$} & \multicolumn{2}{|c|}{ ANOVA } & \multirow{2}{*}{$\begin{array}{c}\text { Post hoc analyses } \\
\text { Scheffe method } \\
(\mathrm{p}<0.05)\end{array}$} \\
\hline & mean & SD & mean & SD & mean & $\mathrm{SD}$ & mean & $\mathrm{SD}$ & $\mathrm{f}$ & $\mathrm{p}$ & \\
\hline CVrr & 4.06 & 1.59 & 4.04 & 1.58 & 4.15 & 1.76 & 4.00 & 1.67 & 0.80 & 0.454 & \\
\hline age & 26 & 8 & 18 & 6 & 29 & 6 & 31 & 6 & 29.38 & 0.000 & $1<2 \& 3$ \\
\hline HR & 94 & 17 & 101 & 15 & 88 & 18 & 81 & 7 & 13.00 & 0.000 & $2 \& 3<1$ \\
\hline $\mathrm{RR}$ & 18 & 3 & 18 & 3 & 19 & 5 & 16 & 3 & 2.26 & 0.112 & \\
\hline $\mathrm{PaCO}_{2}$ & 43.3 & 7.8 & 43.1 & 6.3 & 47.0 & 7.1 & 39.5 & 8.2 & 6.88 & 0.002 & $3<2$ \\
\hline $\mathrm{PaO}_{2}$ & 101.9 & 11.9 & 98.2 & 12.6 & 102.1 & 10.3 & 104.9 & 12.4 & 1.89 & 0.160 & \\
\hline BNP & 54.6 & 113.5 & 52.3 & 160.6 & 49.7 & 81.6 & 61.8 & 99.1 & 0.08 & 0.926 & \\
\hline
\end{tabular}

No-V, no ventilation; NPPV, noninvasive positive pressure ventilation; TPPV, tracheostomy positive pressure ventilation.

CVrr, coefficient of variation of the R-R interval (\%); age, years old; HR, heart rate (/min); RR, respiratory rate (/min).

$\mathrm{PaCO}_{2}$, arterial partial pressure of $\mathrm{CO}_{2} ; \mathrm{PaO}_{2}$, arterial partial pressure of $\mathrm{O}_{2} ; \mathrm{BNP}$, brain natriuretic peptide (pg/mL); $\mathrm{SD}$, standard deviation.

Statistical analyses were done with one way ANOVA and post-hoc analyses with Scheffe method.

Table 2. Correlations between Each Clinical Feature

\begin{tabular}{|c|c|c|c|c|c|c|c|c|c|c|}
\hline & & age & HR & & RR & $\mathrm{PaCO}_{2}$ & & $\mathrm{PaO}_{2}$ & & BNP \\
\hline \multirow[t]{2}{*}{ CVrr } & $\mathrm{r}$ & 0.039 & -0.308 & & -0.075 & -0.573 & & 0.260 & & 0.013 \\
\hline & $\mathrm{p}$ value & 0.743 & 0.008 & \# & 0.530 & 0.000 & \#\# & 0.026 & & 0.916 \\
\hline \multirow[t]{2}{*}{ age } & r & & -0.368 & & -0.119 & 0.004 & & 0.205 & & 0.243 \\
\hline & $\mathrm{p}$ value & & 0.001 & \#\# & 0.315 & 0.976 & & 0.082 & & 0.038 \\
\hline \multirow[t]{2}{*}{ HR } & $\mathrm{r}$ & & & & 0.044 & 0.164 & & -0.329 & & -0.225 \\
\hline & $\mathrm{p}$ value & & & & 0.710 & 0.166 & & 0.004 & \# & 0.056 \\
\hline \multirow[t]{2}{*}{ RR } & r & & & & & 0.174 & & -0.250 & & 0.226 \\
\hline & $\mathrm{p}$ value & & & & & 0.142 & & 0.033 & & 0.054 \\
\hline \multirow[t]{2}{*}{$\mathrm{PaCO}_{2}$} & $r$ & & & & & & & -0.473 & & -0.116 \\
\hline & $\mathrm{p}$ value & & & & & & & 0.000 & \#\# & 0.328 \\
\hline \multirow[t]{2}{*}{$\mathrm{PaO}_{2}$} & r & & & & & & & & & 0.005 \\
\hline & $\mathrm{p}$ value & & & & & & & & & 0.966 \\
\hline
\end{tabular}

CVrr, coefficient of variation of the R-R interval (\%); age, years; HR, heart rate (/min); RR, respiratory rate (/min).

$\mathrm{PaCO}_{2}$, arterial partial pressure of $\mathrm{CO}_{2} ; \mathrm{PaO}_{2}$, arterial partial pressure of $\mathrm{O}_{2} ; \mathrm{BNP}$, brain natriuretic peptide (pg/mL).

Statistical analyses were done with Spearman rank correlation test.

$\#, \mathrm{p}<0.01 ; \#$, $\mathrm{p}<0.001$

and has some correlation with respiratory function $(7,8)$. The above situation in DMD facilitates estimation of hypercapnia using CVrr. In this study, we investigated the relationship between CVrr and hypercapnia and propose that CVrr measurement is one of the useful methods of predicting the hypercapnia in DMD patients.

\section{Patients and Methods}

We studied 73 patients with DMD (age, 6-44 years; clinical features are shown in Table 1). All subjects were admitted to our hospital for evaluation of their cardiopulmonary or neurological conditions. In all patients, the diagnosis was confirmed by a genetic study (abnormality of dystrophin gene) or muscular biopsy (absence of dystrophin protein). All patients became wheelchair-bound by the age of 12 . At the time of our study, 52 patients were supported by mechanical ventilation ( 27 by NPPV and 25 by TPPV) and 21 patients were not (No-V); none of the patients had any signs of lung diseases (e.g. pneumonia, atelectasis, lung edema and so on) on chest X-ray and/or lung computed tomography. Thirty-six patients took medications for chronic heart failure (angiotensin-converting enzyme inhibitor/angiotensin receptor blocker (ACEI/ARB) and $\beta$-blocker, 14 patients; ACEI/ARB only, 20 patients; $\beta$-blocker only, 2 patients).
CVrr, heart rate (HR), respiratory rate (RR), brain natriuretic peptide (BNP), $\mathrm{PaCO}_{2}$ and arterial partial pressure of oxygen $\left(\mathrm{PaO}_{2}\right)$ were measured. Before these measurements, physical conditions in all patients had been checked. If a patient had an unusual condition (high body temperature, HR or RR abnormalities), he was excluded from the present study.

After resting in a supine position for 30 minutes or longer, a standard 12-lead electrocardiography was recorded with an ECG machine (FCP-4101; Fukuda Denshi, Tokyo, Japan), and the R-R intervals were measured for three minutes. From the recorded R-R intervals, the CVrr was obtained by dividing their standard deviation (SD) by the mean (M). Thus, CVrr $(\%)=(\mathrm{SD} / \mathrm{M}) * 100$. Arterial blood gas analysis was also performed just after the ECG recording.

For comparisons of each clinical feature between ventilation types, we used one-factor analysis of variation (ANOVA) and post-hoc analyses by the Scheffe method (Table 1), and Spearman rank correlation test for analysis of the relations between clinical features (Table 2).

\section{Results}

Clinical features of all the patients are shown in Table 1. No-V patients were younger and had a higher HR than the 

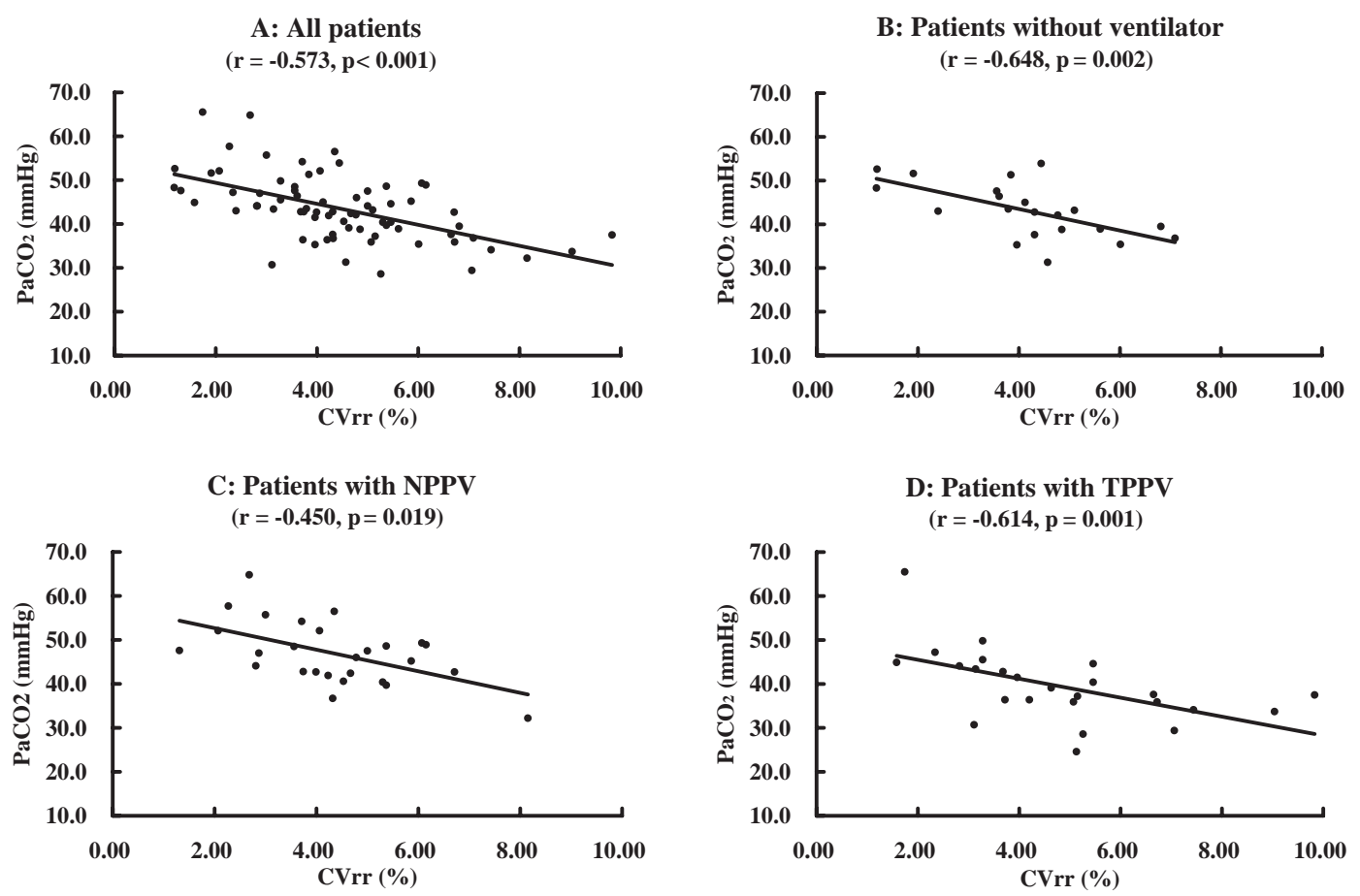

Figure 1. Correlations between the coefficient of variation in the R-R interval (CVrr) and arterial partial pressure of carbon dioxide $\left(\mathrm{PaCO}_{2}\right)$ in DMD patients. A: All DMD patients $(\mathrm{n}=73)$. $\mathrm{B}$ : DMD patients without any ventilator $(n=21)$. C: DMD patients with NPPV $(n=27)$. D: DMD patients with TPPV (n=25). CVrr was negatively correlated with $\mathrm{PaCO}_{2}$ significantly in all DMD patients and in all groups.

other two patient groups. The $\mathrm{PaCO}_{2}$ of TPPV patients was lower than that of NPPV patients.

In analyses of correlations between clinical features (Table 2), there was a significant negative correlation between $\mathrm{CVrr}$ and $\mathrm{PaCO}_{2}$ in all patients (r=-0.573, p<0.001; Fig. 1A) and in any groups of patients (Fig. 1B, C and D). HR was negatively correlated with age and CVrr. As expected, $\mathrm{PaCO}_{2}$ was negatively correlated with $\mathrm{PaO}_{2}$. Between patients with and without medications for heart failure, there were no significant differences in $\mathrm{CVrr}$ (ACEI/ARB, F= 1.415, $\mathrm{p}=0.238$; $\beta$-blocker, $\mathrm{F}=2.837, \mathrm{p}=0.097$ ).

To investigate whether the CVrr is useful for estimating hypercapnia in DMD patients, we classified the patients according to the CVrr and hypercapnia (Table 3). Here, we defined "hypercapnia" as $\mathrm{PaCO}_{2}$ greater than $45 \mathrm{mmHg}(1$, 9), and "severe hypercapnia" as $\mathrm{PaCO}_{2}$ greater than 50 $\mathrm{mmHg}$. We usually use the latter value as a critical respiratory failure, and if a patient shows this value, we should consider further respiratory support $(1,10)$. In 26 DMD patients with a CVrr $>5 \%, 4(15 \%)$ patients were classified as having "hypercapnia". In 15 patients with a CVrr <3\%, 11 (73\%) had "hypercapnia" and 7 (47\%) had severe hypercapnia. This tendency was observed irrespective of respirator support or not.

\section{Discussion}

The conspicuous finding of this study is that the CVrr clearly correlated with the respiratory function of the pa- tient. The low CVrr indicates that respiratory dysfunction is mainly due to hypo-ventilation.

\section{CVrr and $\mathrm{PaCO}_{2}$}

In DMD patients, CVrr was negatively correlated with $\mathrm{PaCO}_{2}$ and HR. Various factors have been reported to affect the CVrr (11-13). In the present patients, the hypercapnia is the most probable factor to explain decreased CVrr. The direct relationship between CVrr and hypercapnia has not been studied in humans. Hypercapnia is well known to increase respiratory neuron firings in the brainstem $(15,16)$ and then increase the respiratory rate and volume $(14,15)$ as well as a reduction of parasympathetic activity (17). Based on these studies (14-17), hypercapnia would decrease the parasympathetic nervous system activity and CVrr. In fact, in an animal study, hypercapnia decreased "high frequency" heart rate variability (8) [i.e. respiratory sinus arrhythmia as measured by spectral power (18)]. The present findings confirm that the same series of events occur in humans.

\section{Positive pressure ventilation effects on CVrr}

In an animal study, acute introduction of positive pressure ventilation sometimes increased the sympathetic activity with a small reduction of parasympathetic activity (19). Regardless of with or without positive pressure ventilation, negative correlations between $\mathrm{CVrr}$ and $\mathrm{PaCO}_{2}$ were present in any groups of DMD patients (Table $3 \&$ Fig. 1). The ventilator effect on CVrr would be small, and would not have affected the negative correlation between $\mathrm{CVrr}$ and 
Table 3. CVrr and Hypercapnia

\begin{tabular}{|c|c|c|c|c|c|c|}
\hline \multirow{3}{*}{ All patients $(n=73)$} & \multicolumn{6}{|c|}{ CVrr } \\
\hline & \multicolumn{2}{|c|}{ smaller than $3 \%(n=15)$} & \multicolumn{2}{|c|}{$3-5 \%(\mathrm{n}=33)$} & \multicolumn{2}{|c|}{ larger than $5 \%(\mathrm{n}=25)$} \\
\hline & Ratio (\%) & $\mathrm{n}$ & Ratio (\%) & $\mathrm{n}$ & Ratio (\%) & $\mathrm{n}$ \\
\hline No hypercapnia $\left(\mathrm{PaCO}_{2}<\right.$ or $\left.=45 \mathrm{mmHg}\right)$ & 27 & 4 & 61 & 20 & 84 & 21 \\
\hline Hypercapnia $\left(\mathrm{PaCO}_{2}>45 \mathrm{mmHg}\right)$ & 73 & 11 & 39 & 13 & 16 & 4 \\
\hline Severe hypercapnia $\left(\mathrm{PaCO}_{2}>50 \mathrm{mmHg}\right)$ & 47 & 7 & 15 & 5 & 0 & 0 \\
\hline Patients without ventilator $(\mathrm{n}=21)$ & \multicolumn{2}{|c|}{$(n=4)$} & \multicolumn{2}{|c|}{$(\mathrm{n}=12)$} & \multicolumn{2}{|c|}{$(n=5)$} \\
\hline No hypercapnia & 25 & 1 & 58 & 7 & 100 & 5 \\
\hline Hypercapnia & 75 & 3 & 42 & 5 & 0 & 0 \\
\hline Severe hypercapnia & 50 & 2 & 17 & 2 & 0 & 0 \\
\hline Patients with NPPV $(\mathrm{n}=27)$ & \multicolumn{2}{|c|}{$(n=7)$} & \multicolumn{2}{|c|}{$(\mathrm{n}=12)$} & \multicolumn{2}{|c|}{$(n=8)$} \\
\hline No hypercapnia & 14 & 1 & 50 & 6 & 50 & 4 \\
\hline Hypercapnia & 86 & 6 & 50 & 6 & 50 & 4 \\
\hline Severe hypercapnia & 57 & 4 & 25 & 3 & 0 & 0 \\
\hline Patients with TPPV $(\mathrm{n}=25)$ & \multicolumn{2}{|c|}{$(n=4)$} & \multicolumn{2}{|c|}{$(n=9)$} & \multicolumn{2}{|c|}{$(n=12)$} \\
\hline No hypercapnia & 50 & 2 & 78 & 7 & 100 & 12 \\
\hline Hypercapnia & 50 & 2 & 22 & 2 & 0 & 0 \\
\hline Severe hypercapnia & 25 & 1 & 0 & 0 & 0 & 0 \\
\hline
\end{tabular}

$\mathrm{PaCO}_{2}$, arterial partial pressure of $\mathrm{CO}_{2}$.

$\mathrm{PaCO}_{2}$ in this study.

\section{Can hypercapnia be estimated by CVrr?}

When CVrr was larger than $5 \%, 84 \%$ of patients had no "hypercapnia". This indicates that most of these patients did not have respiratory problems. In contrast, when CVrr was less than $3 \%$, most of them had respiratory problems. About half of these patients had severe hypercapnia. This indicates that we should carefully examine the respiratory condition in patients with $\mathrm{CVrr}<3 \%$.
In conclusion, we found that CVrr was negatively correlated with $\mathrm{PaCO}_{2}$, and we propose that low $\mathrm{CVrr}$ is one of the signs of respiratory insufficiency in patients with Duchenne muscular dystrophy.

\section{Acknowledgement}

This work was partly supported by a Research Grant (17A-9) for Nervous and Mental Disorders from the Ministry of Health, Labour and Welfare of Japan.

\section{References}

1. Baydur A, Gilgoff I, Prentice W, Prentice W, Carlson M, Fischer DA. Decline in respiratory function and experience with long term assisted ventilation in advanced Duchenne's muscular dystrophy. Chest 97: 884-889, 1990.

2. Rideau Y, Gatin G, Bach J, Gines G. Prolongation of life in Duchenne's muscular dystrophy. Acta Neurol 5: 118-124, 1983.

3. Simonds AK, Muntoni F, Hearther S, Fielding S. Impact of nasal ventilation on survival in hypercapnic Duchenne muscular dystrophy. Thorax 53: 949-952, 1998.

4. Jeppesen J, Green A, Steffensen BF, Rahbek J. The Duchenne muscular dystrophy population in Denmark, 1977-2001: prevalence, incidence and survival in relation to the introduction of ventilator use. Neuromuscul Disord 13: 804-812, 2003.

5. Mochizuki H, Miyatake S, Suzuki M, et al. Mental retardation and lifetime events of Duchenne muscular dystrophy in Japan. Intern Med 47: 1207-1210, 2008.

6. Pagani M, Lombardi F, Guzzetti S, et al. A power spectral analysis of heart rate and arterial pressure variabilities as a marker of sympatho-vagal interaction in man and conscious dog. Circ Res 59: 178-193, 1986.

7. Lanza GA, DelloRusso A, Giglio V, et al. Impairment of cardiac autonomic function in patients with Duchenne muscular dystrophy: relationship to myocardial and respiratory function. Am
Heart J 141: 808-812, 2001.

8. Campen MJ, Tagaito Y, Jenkins TP, Balbir A, O'Donnell CP. Heart rate variability responses to hypoxic and hypercapnic exposures in different mouse strains. J Appl Physiol 99: 807-813, 2005.

9. Misuri G, Lanini B, Gigliotti F, et al. Mechanism of $\mathrm{CO}_{2}$ retention in patients with neuromuscular disease. Chest 117: 447-453, 2000.

10. Nomori H, Ishihara T. Pressure-controlled ventilation via a mini tracheostomy tube for patients with neuromuscular disease. Neurology $\mathbf{5 5}$ : 698-702, 2000.

11. Hayano J, Sakakibara Y, Yamada M, et al. Diurnal variations in vagal and sympathetic cardiac control. Am J Physiol Heart Circ Physiol 258: H642-H646, 1990.

12. Huikuri HV, Niemela MJ, Ojala S, Rantala A, Ikaheimo MJ, Airaksinen KE. Circadian rhythms of frequency domain measures of heart rate variability in healthy subjects and patients with coronary artery disease: Effects of arousal and upright posture. Circulation 90: 121-126, 1994.

13. Lioy F, Hanna BD, Polosa C. Cardiovascular control by medullary surface chemoreceptors. J Auton Nerv Syst 3: 1-7, 1981.

14. Tankersley CG, Fitzgerald RS, Kleeberger SR. Differential control of ventilation among inbred strains of mice. Am J Physiol Regul Integr Comp Physiol 267: R1371-R1377, 1994.

15. Putnam RW, Conrad SC, Gdovin MJ, Erlichman JS, Leiter JC. Neonatal maturation of the hypercapnic ventilatory response and central neural 
$\mathrm{CO}_{2}$ chemosensitivity. Respir Physiol Neurobiol 149: 165-179, 2005.

16. Dean JB, Bayliss DA, Erickson JT, Lawing WL, Millhorn DE. Depolarization and stimulation of neurons in nucleus tractus solitarii by carbon dioxide does not require chemical synaptic input. Neuroscience 36: 207216, 1990.

17. Gilbey MP, Jordan D, Richter DW, Spyer KM. Synaptic mechanisms involved in the inspiratory modulation of vagal cardio-inhibitory neurons in the cat. J Physiol 356: 65-78, 1984.
18. Laude D, Weise F, Girard A, Elghozi JL. Spectral analysis of systolic blood pressure and heart rate oscillations related to respiration. Clin Exp Pharmacol Physiol 22: 352-357, 1995.

19. Fraizier SK, Moser DK, Stone KS. Heart rate variability and hemodynamic alterations in canines with normal cardiac function during exposure to pressure support, continuous positive airway pressure, and a combination of pressure support and continuous positive airway pressure. Biol Res Nurs 2: 167-174, 2001.

(C) 2008 The Japanese Society of Internal Medicine http://www.naika.or.jp/imindex.html 